\title{
Hearing the Voice of the Child through the Storm of the Pandemic: The Impact of COVID-19 Measures on the Detection of and Response to Child Protection Concerns
}

\author{
Jenny Driscoll, Aisha Hutchinson, Ann Lorek, Katrina Kiss, Elise Kinnear \\ School of Education, Communication and Society, King's College London, \\ London, UK \\ jenny.driscoll@kcl.ac.uk(correspondingauthor)
}

\begin{abstract}
COVID-19 and the resulting "lockdown" and social distancing measures significantly disrupted the mechanisms by which child maltreatment may be identified or disclosed and children's voices in relation to their protection are heard. This paper reports on the first stage of a multi-disciplinary study in which 67 interviews were undertaken with strategic and operational leads in all professions with child protection responsibilities from 24 London boroughs in June to early September 2020. Findings highlight disruptions to communication pathways caused by redeployment and the closure of universal and early help services, and concerns about the effectiveness and safety of distanced interactions. Innovations in practice to overcome these challenges are reported, including risk reevaluation exercises, keeping in touch strategies and online innovations. Lundy's model of participation rights is employed to identify lessons for addressing the invisibility of some groups of children, enhancing access to and quality of communication, and embedding responsibility for listening to children.
\end{abstract}

\section{Keywords}

child protection - children's voice-COVID-19-interagency working-care proceedings - safeguarding practice - digital communication - participation rights 


\section{Introduction}

Established good practice in child protection acknowledges the importance of a child-centred systems approach, which recognises children as rights-holders, entitled to participate in decisions about them to a degree commensurate with their age and maturity, in accordance with Article 12 of the United Nations Convention on the Rights of the Child (UNGA, 1989; Munro, 2011; Sidebotham et al., 2016; HM Government, 2018; Levine et al., 2O2O). General Comment No. 12 (UN Committee on the Rights of the Child, 2009) stresses the critical importance of realisation of the right to be heard for the welfare of very young children and for the protection of children from abuse and neglect. In English law, children's wishes and feelings are key factors in the court's deliberations on their welfare, which is the paramount consideration in the court's determination of any matters relating to a child's upbringing (Children Act 1989, s. 1(3)(a)). Children should be seen alone and within their family setting to understand the child's perspective and experiences as well as family relationships and dynamics: failure to observe and hear the child is a common theme throughout Serious Case Reviews (SCR S) (OFSTED, 2011; Myers, 2020). Direct engagement with children and families also allows practitioners to build constructive and trusting reciprocal relationships (Munro, 2011; Sidebotham et al., 2016; HM Government, 2018). Prior to the changes made in response to the Coronavirus pandemic in 2020 and 2021, the home visit was seen to be at the heart of social work practice with children and families: Munro's (2011) call for reprioritising relationship-based social work resulted in a number of initiatives to increase the number of home visits paid to children and families (Winter and Cree, 2016).

But the social distancing regulations imposed to combat the pandemic turned child protection practice upside down, including the mechanisms built in to hear the voice of the child. Established procedures were abruptly undermined by severe reductions in in-person contact between professionals and children and families; closure in full or part of many services, including schools; and widespread redeployment of the safeguarding workforce. This article reports on interviews conducted in London in 2020 during the first stage of a study investigating the impact of COVID-19 measures on English safeguarding and child protection practice. These revealed high levels of anxiety amongst all relevant professional groups in relation to assuring the safety of newly vulnerable, 'hidden' groups of children (such as those confined to their homes and experiencing new exposure to domestic violence, exacerbated 
parental mental ill-health or higher levels of parental substance misuse as a result of increased parental stress) as well as those already known to services. We discuss the predominant barriers to professionals hearing children's voices under the new restraints; adaptations adopted by professionals to overcome those; and the impact of the measures on opportunities for children to have their voices heard and responded to in the particular context of care proceedings. We frame discussion of our findings around Lundy's model for the conceptualisation of children's participation rights to draw out the key elements required for their realisation.

Child Protection under CoviD-19 Lockdown and Social Distancing Measures

\subsection{A Secondary Pandemic of Child Abuse and Neglect?}

The majority of child maltreatment is perpetrated within the home by known family members (Brandon et al., 2020). Social isolation and adverse parental wellbeing and histories are primary risk factors for child abuse and neglect within family environments (Sidebotham et al., 2016; Baird, 2020). "Stay home" legislation therefore exposes children already living in adverse family environments to greater risk (Green, 2020), while many children previously unknown to protective services experience increased household stress, induced by a range of factors including financial distress, job loss and lack of social networks (Adams, 2020). For both groups of children, such risks are compounded by decreased support services. In addition to generic concerns around the effect of the lockdown measures on children's mental health, education and long-term prospects, fears have been raised of a "secondary pandemic" of child abuse and neglect (Crawley et al., 2020; Green, 2020; Adams, 2020). Mechanisms and processes that enable children to disclose concerns and/or professionals to identify children at risk are therefore critical.

\subsection{Adaptations to Child Protection Practice under the Lockdown Measures}

The response to the pandemic affected all established means by which safeguarding concerns are communicated to and amongst professionals. For example, healthcare provider and commissioning decisions to increase capacity for adult CoviD-19 patients disrupted the identification, supervision and multiagency discussion of safeguarding concerns (Green, 2020). Redeployment 
of $5^{\mathrm{O}-70}$ per cent of health visitors provoked collective concern that in the absence of routine contact some children and families would not receive crucial support and new issues would not be identified (Adams, 2020): only 11 per cent of parents of children under two in Saunders and Hoggs' study (2020) had seen a health visitor in person. "Stay home" advice appears to have reduced attendance at hospital Emergency Departments, (Crawley et al., 2020; Lynn et al., 2021; Racher and Brodie, 2020), and General Practice.

For most children, education shifted online as schools closed to all children except those of key workers and children identified as vulnerable. At the time of the interviews, "vulnerable" children were defined as including all children in receipt of statutory services under the Children Act 1989; some children with an Education, Health and Care (EHC) Plan; and other children assessed as vulnerable by educational providers or local authorities (Department for Education (DfE), 2020a). Schools provide safe places for children living in volatile or potentially harmful home environments and opportunities for disclosure (Donagh, 2020). Evidence, including from our study, indicated low attendance by vulnerable children: reasons cited included health concerns; inability to access a place; schools being unable to meet individual children's needs; children refusing to attend; and household shielding (Association of Directors of Children's Services (ADCS), 2020; Disabled Children's Partnership, 2020; Lawson and Elliott, 2020).

Purportedly to reduce the pressure on local authorities, the Government introduced some temporary relaxations in regulation of services to children in state care through the Adoption and Children (Coronavirus) Amendment Regulations 2020. These affected placement arrangements, timescales for visits and the review of care plans as well as allowing children's homes to deprive children displaying symptoms of Coronavirus of their liberty. Although local authority and social work representative bodies were consulted, those representing children, including the Children's Commissioner, whose statutory duty it is to promote and protect the rights of children (Children Act 2004, section 2), were not. As a result, the Court of Appeal declared, after the regulations had expired and been replaced by more limited amendments, that the regulations were unlawful ( $R$ (Article 39) v. Secretary of State for Education, 2020). The original amendments were in place during the fieldwork reported here.

\subsection{The Implications for Children's Article 12 Rights}

For children's Article 12 rights to be fully realised within safeguarding practice, a number of core conditions need to be fulfilled. Lundy (2007) identifies four 
elements for the conceptualisation of Article 12 rights: Space, Voice, Audience and Influence. Her model was motivated by the identified need to ensure that children's participation was meaningful and effective in the sphere of their school lives. "Space" refers to providing opportunities for children to express their views; "Voice" to facilitation of that expression; "Audience", the requirement that adults listen and give due weight to children's views; and "Influence", the appropriate action in response to the child's views. The model has been widely used in other contexts, including safeguarding. It is employed cautiously here, with recognition that there are significant complexities and formidable challenges in implementing children's participation rights within the context of child protection (McCafferty, 2017; Kennan et al., 2018).

\subsubsection{Space: Providing Opportunities to Speak Out}

"Space" in relation to Article 12 is concerned with the need for safe and inclusive spaces where children can speak freely (Lundy, 2007). In social care practice, this includes meeting children in private to provide a safe and child-friendly space for communicating their views; preparing children for important meetings; the role of social outings, play and creative activities in providing opportunities to communicate; building a trusting relationship through time spent together (Kennan et al., 2018); and asking children what matters they want to have a say in (McCafferty, 2017). Implementation of the measures to combat the pandemic deprived children of safe spaces for disclosure in a more literal sense as schools and other services were closed to most children. As the universal service with daily contact with almost all school-aged children, schools are of particular importance in providing opportunities for professionals to develop relationships with children and families and to be sensitive to changes in presentation and demeanour. This is reflected in the high proportion of referrals to children's social care made by schools, alongside health services, to which access was also restricted by the pandemic, and police (Department for Education, 2020c). Early help services, which received greater attention in statutory guidance (HM Government, 2018) following recommendations in the Munro Review (Munro, 2011), also play an important role in ensuring that children identified as in need of additional support have opportunities to communicate with and confide in qualified professionals. Changes in children's exposure to risks as a result of the stay-home regulations and their impact on families' personal and financial circumstances also raised new challenges in ensuring that all children could access pathways to speak out. 


\subsubsection{Voice: supporting Children to Express their Views}

This element is concerned with encouraging children to form views and express them freely, requiring child-friendly information, age-appropriate communication methods, practical assistance for children with language or communication needs (Lundy, 2007; McCafferty, 2017) and access to an advocate or representative as appropriate (Kennan et al., 2018). These pre-requisites were affected by the lockdown and social distancing measures, most notably by the replacement of most in-person interactions by online technology.

\subsubsection{Audience: Listening to Children}

"Listening to children" for these purposes includes both "active" and "effective" listening (Lundy, 2007; Kennan et al., 2018), terms which refer to responding to non-verbal cues as well as the importance of training in communicating effectively and sensitively with children, and a 'guaranteed opportunity to communicate views to an identifiable individual or body with the responsibility to listen' (Lundy, 2007: 937). General Comment No. 12 (Committee on the Rights of the Child, 2009) explicitly acknowledges that Article 12 rights encompass not merely verbal communication of wishes and feelings and the disclosure of maltreatment, but also non-verbal forms of communication, including through play, body language and facial expressions. Many opportunities for professionals to observe children, to pick up signs of discomfort, distress or failure to thrive, were lost through redeployment, including of specialists with specific responsibility for safeguarding, and reduced in-person contact.

\subsubsection{Influence: Acting on Children's Views}

In the context of child protection, "influence" entails a balance of risks and will be determined by professional assessment of the child's welfare: concerns that children have been influenced by parents and the imperative to protect the child may diminish the weight accorded to children's views (McCafferty, 2017). Although our research does not enable us to comment on the extent to which children's views impacted on decisions made, it is notable that impediments to assessment processes will impact on that exercise.

\subsubsection{Article 12.2}

While it is still not common for children to attend court proceedings in person in England, their participation rights in legal proceedings affecting them, articulated in Article 12.2, are given effect in English law by their representation by 
both a guardian ad litem (a specialist independent social worker appointed to ascertain children's wishes and feelings and report those, together with advice as to the child's best interests, to the court) and a solicitor. In light of the enormous importance of the outcome of care proceedings for children's future protection and welfare, we include data on children's Article 12.2 participation rights in this paper.

\section{3}

\section{Methods}

\subsection{Study Design}

The project was conceived as a modified Delphi study in two stages. In the first, selected findings from which are reported here, we aimed to interview up to ten expert informants in London from each of seven professional groups: children's social care, education, law, health, mental health, police, and independent scrutineers or chairs of Safeguarding Partnerships (multi-agency fora responsible for coordination of arrangements to safeguard and promote the welfare of children in their local area). Interview findings informed the second stage survey. The Delphi technique has been widely used in health and social care (Hackett et al., 2006). It was employed because it is particularly suited to areas where research is limited (Iqbal and PiponYoung, 2009). Characteristics include consultation of experts through an iterative process designed to identify salient issues which are then put to the experts in later stages to seek areas of consensus or disagreement (Iqbal and Pipon-Young, 2009). In response to requests by professional groups, the survey stage was extended to England.

Given the relatively small number of eligible participants, in some groups we approached the most senior eligible post-holder in each local authority area for an hour long, semi-structured, qualitative interview. Some referred the request to a colleague (see Table 1), particularly where relevant expertise or experience lay elsewhere. For some groups, such as social care, designated health professionals and education, all interviewees operated within one local authority area, but in others, particularly the police, one post-holder might cover several local authority areas. For that reason and to preserve anonymity, we have not attempted to compare across local authority areas. To select lawyers, we identified well-regarded firms specialising in child and family law based in a range of London localities and invited an experienced senior practitioner to participate. We invited education participants from two groups, to 
TABLE 1 Table of participants by discipline and role

$\begin{array}{lll}\text { Discipline } & \begin{array}{l}\text { Number of } \\ \text { Participants }\end{array} & \text { Role Breakdown \& Codes }\end{array}$

\begin{tabular}{|c|c|c|}
\hline Health (H) & $\begin{array}{l}15 \text { (covering } \\
12 \text { boroughs) }\end{array}$ & $\begin{array}{l}\text { H1-3 Designated Doctors (3) } \\
\text { H4-11 Designated Nurses (8) } \\
\text { H12-15 Named Doctors \& } \\
\text { Nurses (4) }\end{array}$ \\
\hline $\begin{array}{l}\text { Mental Health } \\
(\mathrm{MH})\end{array}$ & $\begin{array}{l}8 \text { (covering } \\
32 \text { boroughs) }\end{array}$ & $\begin{array}{l}\text { MH1-5 Mental health safeguarding } \\
\text { lead [CYP only] (5) } \\
\text { MH6-7 Mental health safeguarding } \\
\text { lead [CYP \& Adults] (2) } \\
\text { MH8 Mental health safeguarding } \\
\text { lead [Adults only] (1) }\end{array}$ \\
\hline Police (P) & $\begin{array}{l}8 \text { (covering } \\
19 \text { boroughs) }\end{array}$ & $\begin{array}{l}\text { P1-6 Detective Superintendents (6) } \\
\text { P7 Detective Chief Inspector (1) } \\
\text { P8 Detective Inspector (1) }\end{array}$ \\
\hline \multicolumn{2}{|c|}{$\begin{array}{l}\text { Children's Social } 11 \\
\text { Care (cSc) }\end{array}$} & $\begin{array}{l}\text { CSC1-5 Directors of Children's } \\
\text { Services (5) } \\
\text { csc6-10 Assistant Directors of } \\
\text { Children's Services (5) } \\
\text { csc11 Child Protection Conference } \\
\text { Chair (1) }\end{array}$ \\
\hline Law (L) & 6 & L1-6 Children's panel lawyers \\
\hline Education (E) & $\begin{array}{l}10 \text { (covering } \\
11 \text { boroughs) }\end{array}$ & $\begin{array}{l}\text { E1-4 Local Authority Directors of } \\
\text { Education/Learning (4) } \\
\text { E5 Local Authority Education } \\
\text { Safeguarding and Exclusions } \\
\text { Lead (1) E6 Local Authority Child } \\
\text { Protection Schools Advisor (1) } \\
\text { E7-9 Headteachers/Designated } \\
\text { Safeguarding Lead (3) E1o } \\
\text { Headteacher/sP DSL Chair (1) }\end{array}$ \\
\hline $\begin{array}{l}\text { Safeguarding } \\
\text { Partnerships } \\
\text { (SP) }\end{array}$ & $\begin{array}{l}9 \text { (covering } 10 \\
\text { boroughs) }\end{array}$ & $\begin{array}{l}\text { SP1-8 Independent chairs/ } \\
\text { scrutineers (8) } \\
\text { SP9 Safeguarding Partnership } \\
\text { manager }(1)\end{array}$ \\
\hline Total & 67 & 24 boroughs \\
\hline
\end{tabular}


glean insights from both local authority senior leaders and headteachers or Designated Safeguarding Leads engaged in the work of their local Safeguarding Partnership. Because we adopted a multi-disciplinary approach, there are relatively small numbers in each group. In total, however, we interviewed 67 strategic and operational leads from 24 London boroughs online between June and early September 2020. Participants were asked questions relating to the impact of CoviD-19 on child safeguarding/protection practice; professional responses to that; and "future proofing" the child protection system. To maintain participants' anonymity, they are referred to solely by their professional group without reference to the borough or boroughs they work in or precise job titles (see Table 1): the breakdown by professional designation and number of boroughs covered in each professional group is provided at Table 1. All participants were working under extreme pressure. We are exceptionally grateful for their time and expert insights. Many reported finding the opportunity for structured reflection valuable.

\subsection{Strengths and Limitations}

The primary strengths of this first stage of the study lie in the expertise, experience and insight of interviewees and the multi-disciplinary design. All participants were senior professionals, including some experts with national oversight. The multi-agency approach elicited a much richer picture than could be gleaned from any single profession of the complexities of hearing the voice of the child in a context which relies heavily on inter-agency collaboration and processes which were abruptly disrupted by measures to tackle the pandemic.

Limitations of the study include the absence of the direct voices of children and young people themselves and their parents and carers. Confining the interviews to London, where additional complexity is introduced through the fragmentation of health services and imperfect geographical alignment of services, may limit the applicability of the findings to other areas of England: the survey stage (data collection February-March 2021) provides national-level data.

Our work is of value in pointing directly to initial gaps in services and barriers to effective practice that stifled the voices of children. However, the situation and professional responses continue to evolve rapidly: data from the national survey stage captures later developments.

In this section we report the most significant barriers to the identification or disclosure of child protection concerns as reported by interviewees, namely 
redeployment; the shift to remote forms of communication; and closure or part closure of key services such as schools and early help. We describe some of the practices that have been implemented to facilitate children's voice in relation to child protection concerns through re-evaluation of individual risks; 'keeping in touch' strategies; and online innovations. We consider the particular challenges for the expression and interpretation of the child's voice in care proceedings. The implications for practice are considered in the discussion, using elements from Lundy's model as a framework.

\section{1 \\ Barriers to Children's Voice created by the Lockdown and Social Distancing Measures}

4.1.1 Redeployment

In line with national trends (Conti and Dow, 2020; Evans, 2020), our participants reported widespread redeployment of frontline health staff, including health visitors, school nurses, community and acute paediatricians, Child and Adolescent Mental Health Service (CAMHs) practitioners, mental health nurses, midwives and other community-based or paediatric health providers, to support adult health care roles (SP2/4/5/9; H1/4/5/6/7/8/9/11/14; MH3/8/9; Csc8). Designated Nurses identified gaps in care arising from poorer links between midwifery and health visiting. Although most areas in our study quickly ensured "eyes on babies" deemed to be vulnerable, picking up perinatal mental health problems at an early stage was flagged as particularly important.

Health staff in safeguarding leadership roles were not immune to redeployment. H8, for example, observed that overnight, senior safeguarding professionals with enormous experience and expertise were redeployed into administrative or care work. Such actions disrupted safeguarding oversight and challenge as well as interagency working relationships and collaboration. Some social care practitioners in early help were moved to support statutory work with high-risk children $\left(\mathrm{E}_{7}\right)$. There was no redeployment for safeguarding officers in the police, following a commitment at commissioner level to maintain staffing levels in safeguarding during the pandemic and draft in additional officers if necessary.

Overall, there was ambivalence about redeployment of practitioners. Many participants felt that, given the anticipated strain on the health service, redeployment and closure of non-essential health services appeared to be "the right thing to do" at the time ( $\left.\mathrm{H}_{15}\right)$, although, as events transpired, redeployment of the child health workforce was often unnecessary. Some areas resisted or rapidly reversed some redeployment decisions, including for health visitors 
(H9; sp6/9). These observations relate to the first lockdown when hospital admissions were considerably lower than in early 2021. However, in addition to loss of access to essential services, there were concerns about loss of specific expertise that may not be recovered ( $\mathrm{MH} 5$ ) and where redeployment impacted heavily on already depleted services ( $\mathrm{H} 9$ ). $\mathrm{M} \mathrm{H} 5$ highlighted a lost opportunity for specialist health staff to support safeguarding during the height of the crisis by, for example, engaging with vulnerable children not in school or responding to exploitation.

\subsubsection{Remote Communication}

At the start of the national lockdown in March 2020, in-person contact between safeguarding professionals and children and families was dramatically and suddenly reduced, with the notable exception of the police, who reported largely continuing to respond in person to direct calls for assistance $\left(\mathrm{P}_{4}\right)$. In-person social work continued in some areas where it was deemed essential (SP5; H1; $\mathrm{CSC} 1 / 2 / 4 / 7 / 8 / 9 / 10)$. Some midwifery continued in person but excluded women's partners (H15): this was observed to have facilitated disclosure of domestic abuse.

Most service provision in all agencies went online, with some initial use of telephone communication. The rapidity of the conversion to online communication in all areas of work is unquestionably one of the most remarkable achievements under the new restrictions. Although participants were largely pleased that services could be provided virtually, they raised concerns about the effectiveness and safety of distanced interactions, arising from loss of the 'human element that you don't necessarily get through a screen' ( $\left.\mathrm{P}_{4}\right)$. Many participants considered that it was not possible for practitioners to communicate with children adequately online due to the importance of non-verbal cues and the social interaction needed to build trust and support children to talk about sensitive matters ( $\left.\mathrm{CsC} 1 / 3 / 4 / 7 / 11 ; \mathrm{H1} / 3 / 11 / 14 / 15 ; \mathrm{P}_{4} ; \mathrm{SP} 7, \mathrm{~L} 3 / 4\right)$. It was 'hard to have difficult conversations over the phone' (H14) and communication with families for whom English is an Additional Language became even more challenging $\left(\mathrm{E}_{3} / 10\right)$.

Many participants were concerned about 'missing something' ( $\left.\mathrm{H}_{15} ; \mathrm{P}_{4}\right)$ :

how can you search for health needs well ... if you're not making the assessment in the room and seeing how they are getting on, how they're holding the baby, how they are functioning with the child? - because those sorts of things will be missed (Hio). 
Risk assessments were a source of particular anxiety, because it is harder to observe and evaluate child-parent interactions online $\left(\mathrm{H}_{3}\right)$. Some participants reported children being judged to be at greater risk when visited in person than had been assessed through remote communication methods, including CsC4, who said that:

it only gives a partial picture. I think for some clients they can present much better online than they're actually doing in reality. So that did create some concerns about risks that go undetected.

CSC11 described a case in which an online review did not confirm that a mother ignored her baby to focus on her toddler, but this was evident in direct observation (see also ADCS, 2021 in relation to neglect). Other practitioners were concerned that it was easier for avoidant or reluctant families to evade scrutiny, and noted difficulty distinguishing between the genuinely anxious and the avoidant.

Many participants (including SP $7, \mathrm{H}_{1} / 3 / 11 ; \mathrm{CSC}_{4} / 7 ; \mathrm{L}_{3} / 4$ ) said it was not safe to have sensitive conversations virtually as you never knew 'who else was in the room' (SP6) but not showing on the screen (see also ADCS, 2021), and it would be impossible to pick up signs of physical abuse online if someone wanted them to be hidden. It is also difficult, and sometimes impossible, to ensure conversations are private: online case conferences where there is domestic abuse were a particular concern (CsC11). Two solicitors described liaising with schools to undertake remote interviews where concerns had been raised about children being overheard at home $\left(\mathrm{L}_{3} / 5\right)$.

A wider concern related to digital poverty, and participants' experience that "digital exclusion" operated to render communication with families in greatest need or children at highest risk more difficult (also noted in ADCS, 2021). Recognising that some children and families do not have access to computers, the Department for Education arranged provision of laptops to children with a social worker and vulnerable Year 10 pupils (age 14-15). The scheme was often felt to work well ( $\left.\mathrm{E}_{4} / 7 ; \mathrm{H} 6 / 7 / 9 ; \mathrm{CSC} 1 / 2 / 7 / 8 / 9 ; \mathrm{E}_{7} ; \mathrm{M} \mathrm{H}_{5}\right)$. However, the government roll-out did not reach many children needing access to the internet as indicated by our participants and summarised by the Children's Commissioner (Children's Commissioner for England, 2020). Our participants described significant challenges in reliable and effective communication online or through social media platforms with some families, due to lack of or poor internet connection, lack of equipment or software and lack of IT skills within many families $\left(\mathrm{E}_{2} / 3 ; \mathrm{CSC} 1 / 4 / 11 ; \mathrm{H} 1 ; \mathrm{L} 2 / 4 / 5\right)$. Examples given by participants include a family of five with one tablet between them (CsC11) and families not being 
contactable by phone or internet $(\mathrm{H} 1)$. Several participants had experienced difficulties in negotiating who would cover the costs involved in facilitating online communication.

While participants recognised that agencies were faced with unprecedented social distancing restrictions and concerns about the spread of the virus, many remained critical of the reluctance of agencies and professionals to reintegrate some in-person provision ( $\left.\mathrm{E}_{7} ; \mathrm{H} 1 / 9 / 11 ; \mathrm{P}_{7} ; \mathrm{SP}_{3} / 5 ; \mathrm{M} \mathrm{H}_{7} ; \mathrm{CsC}_{2} / 8 / 10\right)$, often regarding virtual engagement as a "second class" means of communication that significantly exacerbated the challenges of detecting and evaluating risks to children.

\subsubsection{Universal and Early Help Services}

Opportunities for disclosure or identification of maltreatment were dramatically reduced by the closure of schools to most children, as well as reduced access to Emergency Departments (ED), General Practitioners (GP), early help services, and children's centres. $\mathrm{P} 4$ reported 'a bit more vigilance from the public' but observed 'it still in no way ... covers for not having that school input.' In part, the low attendance of vulnerable children at schools, and reduced or delayed presentation to health services, was considered to be attributable to parents' fears of infection. Child attendances at GP clinics were generally low: H12 noted their experience of only three children in 300 patient encounters over three weeks.

Decisions about the status of early help services during the pandemic must be understood in the context of long-standing concerns over resource allocation and restraints tending to favour statutory services over preventative services and early intervention (Webb and Bywaters, 2018). Early help services before COVID-19 were often holding complex cases (ADCS, 2018), as pressures on statutory services intensified due to austerity measures. Despite evidence of some recent re-investment in early help and significant variation in services across the country (ADCS, 2021), this shift appears to have been exacerbated during the crisis ( $\left.\mathrm{CSC}_{1} / 4 / 5 / 6 / 8 ; \mathrm{P}_{4} ; \mathrm{H}_{1} ; \mathrm{L}_{3} ; \mathrm{SP} 5\right)$. While participants understood why early help staff were redeployed to statutory social care services, some, such as $\mathrm{E}_{7}$, considered early help should have been boosted instead, to ensure ongoing outreach, including in-person visits, where needed.

Initial widespread closure of services (SP3; H6) was followed by a shift to online provision, including for parenting support, Family Support Work, targeted youth work, domestic abuse support, and mother and baby clubs (CSC2/4/5/8/9/10; SP5; H4/6; MH1; L3), dramatically altering children's access to and engagement with safeguarding professionals. Boroughs took a range of different approaches in relation to children's centres, with some remaining 
open, others closing all facilities and others offering a reduced service. In one borough, provision for children under four was kept, while that for older children was offered virtually; this was described as working well. In another, the service remained open for weighing babies and provision of advice to parents, while another kept one centre open for midwifery and as a one-stop shop for domestic abuse support. Some participants commented on the risk of non-engagement once services resumed.

\subsection{Facilitating Children's Voice}

4.2.1 Reassessing and Responding to Risk

At the end of March 2020, the Principal Children and Families Social Worker Network published guidance (Buzzi et al., 2020) advising Social Services to reassess all children and family cases into three categories, where Red indicated 'significant risk of serious harm, injury or death'; Amber 'moderate risk of either emotional or physical harm or neglect'; and Green 'low risk of harm or neglect for the child' ("RAG rating"). Reassessment was to consider the implications for children's safety in the event that no professional was able to have in-person contact with the children and their family and/or a review meeting could not be held, or not attended by the family within the next four weeks.

Discussions around children's revised risk status took place both uni-professionally and in a number of boroughs on an interagency basis. When other agencies such as CAMHS were involved, this took some time to establish, but discussions rapidly escalated as the benefits became apparent, particularly with some increasing complexity of cases. Where RAG Rating was undertaken at Safeguarding Partnership level, the exercise was complex but regarded as valuable (sp6): conversely, the absence of a single shared list of vulnerable children undermined confidence in monitoring and support $\left(\mathrm{H}_{2}\right)$. However, these exercises could not assuage the considerable anxiety expressed by many participants about the risks to children in changed home circumstances who, in the absence of ordinary interactions between children and professionals, would remain "hidden" until normal life resumed. Domestic abuse has been a focus of many attempts to identify new groups at risk of harm and participants recounted many initiatives to facilitate reporting, such as the use of code words in shops. However, as $\mathrm{P}_{5}$ pointed out, these did not provide an opportunity for children to disclose directly.

Various strategies were recounted to provide more opportunities for contact and communication with groups likely to be at additional risk, including changes to local Health Visiting guidance to provide more "eyes" on babies, such as opportunities to weigh at clinics. Following national General Practice guidance (RCGP, 202O) to continue immunisations and baby checks, 
immunisation uptake picked up somewhat (McDonald et al., 2020), a significant point because General Practice was almost the only forum through which professionals routinely met most mothers and babies in person in the first months of life. One local authority re-opened youth centres for targeted work with young people and to offer them a space to meet youth workers.

\subsubsection{Keeping in Touch With Families of Children Not in School}

Regular, generally weekly, calls to "check in" with vulnerable children not in school were undertaken by social care or education professionals in many boroughs, amounting to a 'huge increase' in contacts with known vulnerable children and families (SP4/5), although not all families engaged willingly. Some schools retained less frequent contact over the summer holidays. For more vulnerable groups, additional contact was sometimes instituted. E5 described daily contact with parents who were struggling, and home visits, providing continued opportunities to speak with children, listen to their experience and hear their concerns. E7, the headteacher of a Pupil Referral Unit, introduced daily contact with all families and weekly in-person visits, undertaken by tutors for those in the Green risk group and Designated Safeguarding Leads for those categorised as Red or Amber. She felt strongly that problems only came to light from in-person contact and that should have been instituted earlier and more widely. E2 commented:

that keep[ing] in contact was crucial, there was nothing sexy or innovative about it, it was about being tenacious ... they kept visibility, they went and visited where they possibly could with an excuse ... they kept that profile high and they kept it all the way through and I know they were exhausted by keeping that vigilance.

As the crisis continued, a range of creative in-person opportunities were created such as doorstep visits, meetings in gardens and parks, and walking on the street $\left(\mathrm{CsC}_{4} / 5 ; \mathrm{Hg} / 10\right)$. In one local authority, failures to establish contact by schools would result in referral to children's social care.

\subsubsection{Online Innovation}

Throughout the interviews, participants described the rapid adoption of technological means, including text messaging and WhatsApp, to maintain professional contact with children and families at a distance, some of which arguably make regular communication much easier and led to suggestions that some areas had more contact with, and "eyes on", known vulnerable children than ever before $\left(\mathrm{H}_{4} / 5\right)$. Some local authorities described supplementing 
the government laptop scheme $\left(\mathrm{CsC}_{3} / 9\right)$ or redistributing spare devices from schools (E2) to ensure children and families could communicate with children's services.

Some children and young people were also found to be more communicative online and engaging well (SP2/6/9; $\mathrm{H} 1 / 4 / 13 / 14 ; \mathrm{MH} 1 / 3 / 8, \mathrm{L1} / 2 / 3$, CSC1/2/4/7/8/11). Technology worked particularly well for those who struggled to engage in person or where travel or time pressures presented challenges to accessing conventional services.

An area where online communication had not previously been considered appropriate but was often found to be effective was work with Looked After Children (LAC). Virtual contact was enjoyed by some LAC (SP5/7; H11/14; $\mathrm{MH}_{7}$; $\left.\mathrm{CSC}_{2} / 8\right)$, especially those reluctant to acknowledge their care status (csc8). Communication with children in distant placements improved and it was observed that LAC cannot avoid meetings online so easily (H14). Other support included increased contact with Independent Reviewing Officers (IRO S). CSC1O recounted increasing the frequency of contact with care leavers from monthly or bi-monthly to fortnightly in response to concerns about isolation and loneliness: an internal survey undertaken in their area showed 80 per cent enjoyed and welcomed the additional virtual contact. For the most part our interviewees reported only taking advantage of the statutory relaxations where unavoidable, primarily as a matter of principle, although some cited concerns about the forthcoming judicial review and one interviewee took the view that children in care were no less a concern that those subject to child protection plans.

\subsection{Article 12.2: the Voice of the Child in Care Proceedings}

Legal participants $(\mathrm{L} 1 / 3 / 4 / 6)$ and others $\left(\mathrm{SP} 2 / 3\right.$; $\left.\mathrm{CSC}_{3} / 9 / 11\right)$ reported lengthy delays and backlogs in court business in part due to an increased volume of litigation responses where local authorities were concerned about the safety of children they were unable to monitor adequately. Delays were accompanied by reduced in-person contact with social workers, remote-only communication with the guardian ad litem and reduced and/or often strained online contact between children and their families. Cumulatively, these might influence children's wishes and feelings in relation to their future. Solicitors described how taking directions from their child clients, talking through difficult decisions and potential outcomes from proceedings, and supporting children to express their wishes and feelings were more challenging through remote means. L3 explained:

one of the more difficult things for me ... is where their instructions aren't clear. And I wouldn't necessarily expect them to be clear, but if I can sit 
down and have a chat with them over a period of time, then often we can get to the bottom of it. I'm not able to do that to that extent on a remote platform.

Courts have struggled to adapt to online or hybrid provision (Ryan et al., 2020). Parents have reported difficulties in understanding and following the proceedings and professionals cite concerns about demonstration of empathy and support (Ryan et al., 2020). Our participants expressed misgivings about the appropriateness of remote court hearings for the assessment of evidence and because of the stressful and high-stakes nature of the proceedings. Social distancing measures could also impact on the collection and quality of evidence and lead to delays (L1). Some expert assessments were cancelled or delayed as a result of concerns that remote assessments of parenting capacity and of children might be less reliable and one solicitor commented that perhaps some experts gave the parents the benefit of the doubt more. Conversely, one lawyer suggested that these factors, coupled with concerns about adequate monitoring of risk and reduced scope for alternative plans such as kinship placements, may have affected the outcomes of some hearings, especially for babies (L4).

Two potential benefits of online communication were identified, however. The first was the greater scope for lawyers to "check-in" with child clients between hearings (L5). The second arose from a description of a child's very successful Zoom meeting with a judge for which the child had prepared carefully. Such meetings may be less intimidating for children than in-person attendance at the judge's chambers, but it was acknowledged that some judges may be more successful than others in managing virtual meetings with children. Notable here too is judicial commentary that remote access has given judges new insights into children's living arrangements and family life (see, for example, Mr Justice Hayden in University Hospitals Bristol and Weston NHS Foundation v. Godfrey and Godfrey (2021)).

Our findings highlight the extent to which the restrictions imposed to combat the spread of COVID-19 gave rise to unintended consequences for safeguarding and child protection. Participants displayed some anger, echoing the Children's Commissioner's view, that a focus on adult health policy resulted in a disregard for children and young people's safety and wellbeing (Children's Commissioner for England, 2020), with $\mathrm{MH}_{5}$ noting that, 'safeguarding was 
virtually invisible in emergency planning'. It is critical that lessons are learnt for the future. Three areas demand attention: first, addressing means through which otherwise "hidden" children come to the attention of safeguarding professionals (Space); second, attention to access to and quality of communication with children and families (Voice); and third, ensuring effective listening by professionals, including through "eyes on children" (Audience).

\subsection{Space: Opportunities for Disclosure and "Hidden" Children}

Three areas stand out in relation to safe spaces and opportunities for disclosure. First, the pandemic has served to highlight the impact of digital poverty on all forms of social exclusion. While the implications go beyond concerns about communication between children and professionals in the immediate term to impact on children's education and long-term prospects, it is vital that digital inequality is addressed to ensure that all children have equal access to means through which they can communicate with safeguarding professionals. Second, anxiety over contact with vulnerable children not in school has served as a reminder of groups of children for whom schools do not have oversight, and in particular those who are home-schooled, a practice that is poorly regulated in England, giving rise to significant concern that their voices are unheard. It is yet to be seen whether fears of an increase in home-schooled children where families are concerned about what children might say on return to school or who have enjoyed the lack of routine will be realised. Third, the tendency for early help services to be sacrificed in favour of statutory services in response to crises has long been a weakness of the English child protection system. The pandemic has once again illustrated the importance of early help in facilitating the voice of the child and responding before matters escalate. It is to be hoped that Josh MacAlister's review of children's social services (GOV. UK, 2021) will take the opportunity offered to address lessons from the crisis.

\subsection{Voice: Access to and Quality of Communication}

Participants recognised many benefits of remote communication, particularly for professional communication, which are not reported here (but see, for example, Pearce and Miller, 2020). Our study, like Baginsky and Manthorpe (2020), Ferguson et al. (2020), Pearce and Miller (2020) and Racher and Brodie (2020), has shown that some young people engaged better with remote technology than in-person contact in some contexts. Our participants cited clear advantages where children are out of area or where frequent, short "checkins" may be reassuring for children and/or professionals. But children and parents appear to have found remote court proceedings, in particular, challenging and sometimes distressing (see also Ryan et al. (2020), to which parents 
contributed). Understanding how best use can be made of new technologies without compromising safety would be a fruitful area for further research, while training for professionals in remote engagement with children and families, including awareness of the potential pitfalls of remote risk assessments and rapport-building online, will be an important means of both helping to ensure children's safety and boosting professional confidence. While recognising the potential for supplementing physical visits with online contact, some participants felt strongly that aspects of work with children and families cannot adequately be undertaken by digital means. There were calls for more safe spaces to enable children to disclose abuse and neglect, and continuation of more in-person visits.

A child-centred approach to strengthening the resilience of the child protection system against future crises must examine how children can be empowered to seek and access help when they need it, regardless of their personal circumstances, through provision of resources, relationships, knowledge and skills. Childline, for example, has introduced an app through which children can communicate securely with protective adults. Future research might explore the effectiveness of attempts to encourage children to discuss their welfare and share concerns while educated at home and boosting age-appropriate teaching that enables children to understand healthy relationships and detect abusive conduct.

\subsection{Audience: Ensuring Responsibility for Listening to Children}

At the time of writing, there is emerging evidence that patterns of redeployment in the later part of 2020 took into account the concerns arising in the middle of the year. While logistical challenges may be considerable, the core principle that staff with safeguarding leadership responsibilities should not be redeployed is incontrovertible and there appears to be universal agreement that core midwifery and health visiting services must also be preserved. Risk assessments should be undertaken before redeployment of safeguarding professionals and decisions made in conjunction with local safeguarding leads.

As our interviews ended, schools were reopening at the start of the new academic year in September. Participants in later interviews spoke about the importance of additional training to support staff to pick up signs and signals of maltreatment and distress and to ensure opportunities and avenues through which children could disclose or discuss any concerns and worries on their return. But life did not return to normal. The last quarter of 2020 and the first of 2021 have seen a second, more brutal, wave of infections and return to extended restrictions and lockdowns. For most families and policymakers, the primary focus in the coming months appears, understandably, to be redressing 
the educational deficit that children - particularly those in disadvantaged families - have suffered. The pandemic has therefore exacerbated the pre-existing tension between schools' primary function as educational providers and their pastoral responsibilities. It is vital that the political drive to improve educational outcomes as the pandemic recedes is not allowed to impede the critical safeguarding work of schools.

\subsection{Influence}

We are not able to assess the extent to which children's expressions of voice impacted on the child protection response. However, our data on child protection proceedings suggest that delay, challenges in contact arrangements, complexity and uncertainty may colour children's views as well as advocates' understanding of their perspectives, rendering more difficult the task of assessing the extent to which children's views should influence the outcome of proceedings.

Overall, the effect of practice changes on the identification of child protection concerns is evidenced by initial falls in the number of referrals made to children's social care. Referral rates vary across local authorities (Bilson and Martin, 2017) and over the course of the year in regular patterns, which include troughs coinciding with school holiday periods (Department for Education, $2020 \mathrm{c}$ ). While the reasons behind changes in referral patterns raise contentious issues, it is pertinent to note that the first week of September, when the new academic year started (and our interviews ended), saw approximately a 13 per cent reduction in referrals compared with the same period in recent years (Department for Education, 2020b): some of our interviewees reported much greater falls in June-August of up to 40 per cent over a quarter. Twothirds of child and family social workers responding to a British Association of Social Workers (BASW) survey (2021) reported an increase in referrals and/ or their caseload following the reopening of schools in September 2020. Increased complexity and/or seriousness of referrals, reported by our participants and also found by Baginsky and Manthorpe (2020) and Pearce and Miller (2020), may in part reflect delayed identification.

It is apparent from our study that failure to realise children's Article 12 rights in safeguarding work may have serious implications not only for their right to protection, but also to a fair trial and to family life, including, for some children, ongoing contact with birth families. As we learn to "live with" rather than 
"overcome" the Coronavirus as it mutates, the challenges facing the child protection system are formidable, as the fallout from the pandemic and the measures taken to control it manifest in increased poverty and homelessness; greater adult and child mental ill-health; diminished prospects for young people; and rising rates of alcoholism and domestic abuse. At the time of writing, social workers were bracing for an anticipated "tsunami" of referrals to children's social care when schools open more widely (BASW, 2021). Yet frontline child protection professionals in all disciplines are battling exhaustion and burnout. Smarter working practices, recognising the potential to increase safe spaces and drawing on the aspects of remote work that young people enjoy and engage well with to amplify and facilitate voice will be needed, while recognising that there are areas of work that require direct engagement to build and maintain trust and pick up vital cues and clues. Children's views on adaptations and new ways of working should be a priority for future research. As the pandemic recedes, the opportunity to reassess and strengthen the mechanisms through which children's voices reach the ears of safeguarding professionals must not be lost.

\section{Acknowledgements}

The authors are extremely grateful to Professor Andrea Danese, Professor of Child and Adolescent Psychiatry at the Institute of Psychiatry, Psychology and Neuroscience, King's College London; Professor Gillian Douglas, former Dean of the Dickson Poon School of Law at King's College London; and Professor Jenny Pearce for their invaluable advice and support in the design and execution of the study, as well as to the expert partners: Her Honour Judge Carol Atkinson, Designated Family Judge for East London; Ds Steve Clancy of the Metropolitan Police Continuous Policing Centre (Safeguarding Strand); and Annie Hudson, former Strategic Director, Children's Services, London Borough of Lambeth and Chair of the National Child Safeguarding Practice Review Panel. Any errors are those of the authors.

For any questions about the ongoing project including survey findings, please contact jenny.driscoll@kcl.ac.uk.

\section{References}

Adams, C., "Is A Secondary Pandemic on Its Way?", Institute of Health Visiting, 6 April 2020. Available at: https://ihv.org.uk/news-and-views/voices/is-a-secondarypandemic-on-its-way/. Accessed on 15 November 2020. 
Baginsky, M. and Manthorpe, J., "Managing through Covid-19: the experiences of children's social care in 15 English local authorities" (London: King's College London, 2020): https://bettercarenetwork.org/sites/default/files/202O-07/Report\%2O-\%2O Managing\%2othrough\%20COvid-19\%2ofinal\%202\%20July.pdf.

Baird, E., "Non-Accidental Injury in Children in the Time of Covid-19 Pandemic", British Orthopaedic Association, 8 April 2020. Available at: https://www.boa.ac.uk/ resources/knowledge-hub/non-accidental-injury-in-children-in-the-time-ofcovid-19-pandemic.html.

Bilson, A. and Martin, K., "Referrals and child protection in England: One in five children referred to children's services and one in nineteen investigated before the age of five", The British Journal of Social Work 2017 (47(3)), 793-11: https://doi. org/10.1093/bjsw/bcw054.

Brandon, M., Sidebotham, P., Belderson, P., Cleaver, H., Dickens, J., Garstang, J., Harris, J., Sorensen, P. and Wate, R., "Complexity and Challenge: A Triennial Analysis of SCR S 2014-2017" (Department for Education, 2020): https://www.gov.uk/government/ publications/analysis-of-serious-case-reviews-2014-to-2017.

British Association of Social Workers (BASW), "Social work during the Covid-19 pandemic: initial findings" (Birmingham: BASw, 2021): https://www.basw.co.uk/ system/files/resources/basw_social_working_during_the_coviD_19_pandemic_ initial_findings_26.o1.21.pdf.

Buzzi, P., Megele, C., Blackmore, S., "The Principal Children and Families Social Worker (PCFSW) Network Best Practice Guide for Risk Assessment and Prioritising Children and Families' Needs During Pandemic: May 2020 Update" (PCFSW, 2020): https:// whatworks-csc.org.uk/wp-content/uploads/PSW-and-SWE-Best-Practice-Guidefor-Prioritizing-Children-and-Families-Needs-and-Risks-20200505-2.pdf.

Children Act 1989, c. 41. Available at: https://www.legislation.gov.uk/ukpga/1989/41/ contents.

Children Act, 2004, c. 31. Available at: https://www.legislation.gov.uk/ukpga/2004/31/ contents.

Children's Commissioner for England, "Childhood in the Time of covid" (London: Children's Commissioner for England, 2020): https://www.childrenscommissioner. gov.uk/wp-content/uploads/2020/o9/cco-childhood-in-the-time-of-coviD.pdf.

Conti, G. and Dow, A., "The Impacts of CoviD-19 On Health Visiting in England: First Results September 2020" (London: UCL, 202O): https://discovery.ucl.ac.uk/id/ eprint/10106430/8/Conti_Dow_The\%2oimpacts\%2Oof\%2OC OvID-19\%2oon\%2O Health\%2oVisiting\%2oin\%2oEngland\%2O25092o.pdf.

Crawley, E., Loades, M., Feder, G., Logan, S., Redwood, S. and Macleod, J., "Wider Collateral Damage to Children in the UK because of the Social Distancing Measures Designed to Reduce the Impact of COVID-19 in Adults", BMJ Paediatrics Open 2020 (4(1)), 1-4. DOI: 10.1136/bmjpo-2020-000701. 
Department for Education, "Supporting Vulnerable Children and Young People During the Coronavirus (COVID-19) Outbreak - Actions for Educational Providers and Other Partners" (Department for Education, 2020a): https://www.gov.uk/government/ publications/coronavirus-COVID-19-guidance-on-vulnerable-children-and-youngpeople/coronavirus-COVID-19-guidance-on-vulnerable-children-and-youngpeople. Accessed on 13 November 2020.

Department for Education, "Vulnerable Children and Young People Survey: Summary of returns Waves 1-10: October 2020" (Department for Education, 2020b): https://assets.publishing.service.gov.uk/government/uploads/system/uploads/ attachment_data/file/925470/VCYP_Survey_publication_W1o.pdf.

Department for Education, "Characteristics of Children in Need: 2019 to 2020" (Department for Education, 2020c): https://explore-education-statistics.service. gov.uk/find-statistics/characteristics-of-children-in-need/2020.

Disabled Children's Partnership, “The Return to School for Disabled Children after Lockdown” (London: Disabled Children's Partnership, 2020): https:// disabledchildrenspartnership.org.uk/wp-content/uploads/2020/11/Back-to-schoolpoll-report.pdf.

Donagh, B., "From Unnoticed to Invisible: The Impact of covid-19 on Children and Young People Experiencing Domestic Violence and Abuse", Child Abuse Review 2020 (29(4)), 387-391. DOI: 10.1002/car.2649.

Evans, N., "COviD-19: How Redeployment is Affecting Children's Services", Nursing Children and Young People 2020 (32(3)), 8-9. DOI: 10.7748/ncyp.32.3.8.s7.

Ferguson, H., Kelly, L. and Pink, S., "Research Briefing Two: Disruption and Renewal of Social Work and Child Protection During covid-19 And Beyond" (Birmingham: University of Birmingham, 2020): https://www.birmingham.ac.uk/documents/ college-social-sciences/social-policy/publications/research-briefing-2-childprotection-disruption-renewal-accessible.pdf.

Gov.UK. 2021. Independent Review of Children's Social Care: https://www.gov.uk/ government/groups/independent-review-of-childrens-social-care\#about-thereview. Accessed on 18 February 2021.

Green, P., "Risks to Children and Young People During Covid-19 Pandemic", BMJ 2020 369(1669), 1-2. DOI: 10.1136/bmj.m1669.

Hackett, S., Masson, H. and Phillips S., "Exploring Consensus in Practice with Youth Who Are Sexually Abusive: Findings from a Delphi Study of Practitioner Views in the United Kingdom and the Republic of Ireland", Child Maltreatment 2006 (11(2)), 146-156. Doi:10.1177/1077559505285744.

нм Government, "Working Together to Safeguard Children: A Guide to Inter-Agency Working to Safeguard and Promote the Welfare of Children" (HM Government, 2018): https://www.gov.uk/government/publications/working-together-to-safeguardchildren--2. 
Iqbal, S. and Pipon-Young, L., "The Delphi Method", The Psychologist 2009 (22): 598-6o1. https://thepsychologist.bps.org.uk/volume-22/edition-7/delphi-method.

Kennan, D., Brady, B. and Forkan, C., "Space, Voice, Audience and Influence: The Lundy Model of Participation (2007) in Child Welfare Practice", Practice 2018 (31(3)), 205-218. DOI: 10.108 o/o9503153.2018.1483494

Lawson, K. and Elliott, D., "Education during the COVID-19 pandemic and transitioning back to school: Experiences of the fostering sector" (London: The Fostering Network, 2O2O): https://www.thefosteringnetwork.org.uk/policy-practice/research/ education-during-COVID-19-pandemic-and-transitioning-back-school.

Levine, D. T., Morton, J. and O'Reilly, M., "Child safety, protection, and safeguarding in the time of CoviD-19 in Great Britain: Proposing a conceptual framework", Child Abuse \& Neglect 2020 (110(Part 2)), 1-9. DOI: 10.1016/j.chiabu.2020.104668.

Lundy, L., " 'Voice' is not enough: conceptualising Article 12 of the United Nations Convention on the Rights of the Child", British Educational Research Journal 2007 (33(6)), 927-942. DOI: 10.1080/o1411920701657033

Lynn, R., Avis, J., Lenton, S., Amin-Chowdhury, Z. and Ladhani, S., "Delayed Access to Care and Late Presentations in Children During the Covid-19 Pandemic: a snapshot survey of 4075 paediatricians in the UK and Ireland", Archives of Disease in Childhood 2021 (106(2)), 1-2. DOI: 10.1136/archdischild-2020-319848.

McCafferty, P., "Implementing Article 12 of the United Nations Convention on the Rights of the Child in Child Protection Decision-Making: a Critical Analysis of the Challenges and Opportunities for Social Work", Child Care in Practice 2017 (23(4)), 327-341. DOI: 10.108o/13575279.2016.1264368

McDonald, H., Tessier, E., White, J., Woodruff, M., Knowles, C., Bates, C., Parry, J., Walker, J., Scott, J., Smeeth, L., Yarwood, J., Ramsay, M. and Edelstein, M., "Early impact of the coronavirus disease (COVID-19) pandemic and physical distancing measures on routine childhood vaccinations in England, January to April 2020", Eurosurveillance 2020 (25(19)), 1-6. DOI: 10.2807/156o-7917.ES.2020.25.19.200o848.

Munro, E., The Munro Review of Child Protection: Final Report (London: Department for Education, 2011).

Myers, J., "2019 Triennial Analysis of Serious Case Reviews: Local Safeguarding Partnerships" (Devon: Research in Practice, 2020): https://seriouscasereviews.rip. org.uk/wp-content/uploads/2019_triennial_analysis_of_serious_case_reviews_ local_safeguarding_partnerships_Mar2o2o.pdf.

Office of National Statistics (ons), Domestic abuse during the coronavirus (COVID-19) pandemic, England and Wales (2020): https://www.ons.gov.uk/peoplepopulation andcommunity/crimeandjustice/articles/domesticabuseduringthecorona virusCovid19pandemicenglandandwales/november2O2O.

Ofsted, The voice of the child: learning lessons from serious case reviews: A thematic report of Ofsted's evaluation of serious case reviews from 1 April to 30 September 2010 (2011): 
https://assets.publishing.service.gov.uk/government/uploads/system/uploads/ attachment_data/file/526981/The_voice_of_the_child.pdf. Accessed 6 April 2021.

Pearce, J. and Miller, C., "Safeguarding children under Covid-19: What are we learning?", Journal of Children's Services 2020 (15(4)), 287-293. Doi: 10.1108/JCS-o6-2020-0021.

Racher, A. and Brodie, I., "Joining the dots? Tackling child exploitation during CoviD-19", Journal of Children's Services 2020 (15(4)), 275-285. Doi: 10.1108/JCS-07-2020-0036.

Royal College of General Practitioners (RCGP), "RCGP Guidance on Workload Prioritisation During COVID-19 [v.8]" (British Medical Association \& RCGP, 2O2O): https://www.rcgp.org.uk/-/media/Files/Policy/A-Z-policy/2020/Covid19/RCGPguidance/202003233RCGPGuidanceprioritisationroutineworkduringCOVIDFINAL. ashx?la=en.

Ryan, M., Harker, L. and Rothera, S., "Remote Hearings in the Family Justice System: Reflections and Experiences - Follow-up Consultation September 2020" (London: Nuffield Family Justice Observatory, 2020): https://www.nuffieldfjo.org.uk/app/ nuffield/files-module/local/documents/remote_hearings_sept_202o.pdf.

Saunders, B. and Hogg, S., "Babies in Lockdown: Listening to Parents to Build Back Better" (Best Beginnings, Home-Start UK \& the Parent-Infant Foundation, 2020): https://babiesinlockdown.files.wordpress.com/2020/o8/babies-in-lockdown-mainreport-final-version.pdf.

Sidebotham, P., Brandon, M., Bailey, S., Belderson, P., Dodsworth, J., Harrison, E., Retzer, A. and Sorenson, P., "Pathways to Harm, Pathways to Protection: A Triennial Analysis of Serious Case Reviews 2011 To 2014" (Department for Education, 2016): https://www. gov.uk/government/publications/analysis-of-serious-case-reviews-2011-to-2014.

The Association of Directors of Children's Services (ADCS), "Research Report: Safeguarding Pressures Phase 6" (Manchester: ADCs, 2018): https://adcs.org.uk/ safeguarding/article/safeguarding-pressures-phase-6.

The Association of Directors of Children's Services (ADCs), "Elective Home Education Survey 2O2O” (Manchester: ADCs, 2020): https://adcs.org.uk/assets/documentation/ ADCS_EHE_Survey_2020_FINALweb.pdf.

The Association of Directors of Children's Services (ADCS), "Research Report: Safeguarding Pressures Phase 7" (Manchester: ADCs, 2021): https://adcs.org.uk/ safeguarding/article/safeguarding-pressures-phase-7.

United Nations Committee on the Rights of the Child, The Right of the Child to be Heard, General Comment No. 12 (2009). CRC/C/GC/12.

United Nations General Assembly (UNGA), 1989. Convention on the Rights of the Child, United Nations.

Webb, C. and Bywaters, P., "Austerity, Rationing and Inequity: Trends in Children's and Young Peoples' Services Expenditure in England between 2010 and 2015", Local Government Studies 2018 (44(3)), 391-415. Doi: 10.108o/03003930.2018.1430028. 
Winter, K. and Cree, V., "Social Work Home Visits to Children and Families in the UK: A Foucauldian Perspective”, The British Journal of Social Work 2016 (46 (5)), 1175-119o. Doi.org/10.1093/bjsw/bcvo69.

\section{Case law}

$R$ (Article 39) v. Secretary of State for Education [2020] EWCA Civ 1577. Available at: https://www.judiciary.uk/judgments/r-article-39-v-secretary-of-state-for-education/. Accessed 6 April 2021.

University Hospitals Bristol and Weston NHS Foundation v. Godfrey and Godfrey [2020] EWHC 163 (Fam): https://www.bailii.org/ew/cases/EWHC/Fam/2021/163.html. Accessed 8 April 2021. 